\title{
Meaning and Use: Drama and the Aesthetic
}

\author{
Leon Culbertson (ORCID ID: 0000-0002-9101-5851)
}

\begin{abstract}
This paper considers David Best's claim that descriptions of events in sport as being 'dramatic' or 'tragic' employ those terms in a figurative sense, along with Stephen Mumford's rejection of that view. The paper begins by outlining Mumford's argument before locating the nature of Best's argument in an elaboration of Philosophical Investigations $§ 43$ and Wittgenstein's wider employment of the concepts of a language-game and a form of life. It then looks closely at different uses of the term 'dramatic' before elaborating Best's description of the conventions of drama in brief discussion of uses of the terms 'tragic', 'illusion' and 'emotion' and their cognates, while considering the implications of those for Mumford's distinction between what he calls 'real and imagined drama'. The paper then stresses some important differences between sport and drama, before concluding with some remarks on how we might understand descriptions of sport as being dramatic, and on the origins of the confusion in relation to this issue as being in the construction of philosophical theories.
\end{abstract}

KEYWORDS aesthetics of sport; drama; language-games; meaning and use; the drama argument; Wittgenstein.

\section{Introduction}

David Best (1978) argued that when we describe events in sport as 'dramatic' or 'tragic', we are using those terms in a figurative way, and not in the way in which they are used in the theatre (or, we might add, in film or television drama). As Best didn't give his argument a name, I have denominated it 'the drama argument' (Culbertson, 2017). The rejection of the drama argument is central to Stephen Mumford's articulation and defence of what he calls 'purism' in sport spectatorship. Mumford's focus is on drama because the location of drama in sport is regarded by him as evidence that there is a clear aesthetic dimension to sport, which is part of the case he makes for the claim that the purist way of watching sport focuses principally on aesthetic properties of sport.

Mumford thinks that not only is sport dramatic, but that the drama in sport is 'real drama', as opposed to the 'imagined drama' of the theatre, film and television (2012: 49ff.). Importantly, for Mumford (2012), whether the drama is real or imagined seems to be the only significant difference between drama in sport and drama in the theatre, film or television. In other words, he treats drama as if, in describing something as 'dramatic', our use of the term 'dramatic' makes the same contribution to the sense of the sentence, regardless of whether the drama is in sport or in the theatre, film or television. That seems strange because one might have thought, and indeed, it seems likely that Best would have thought, that 
someone who thinks there is a difference between real and imagined drama has noticed a difference that should be reflected in his or her view of the connection between the drama in each case and the aesthetic.

A question one might feel drawn to ask here is 'What does the difference between "real" and "imagined" drama consist in?" The answer to that cannot be that one is real and the other is imagined, for that is simply to beg the question, yet that appears either to be the answer Mumford seems to want to give, or he simply doesn't give us any clues as to what alternative answer he would give. Indeed, he thinks that there is no sharp distinction between the two, but he must think that there is a fuzzy distinction nonetheless because he regularly distinguishes between 'real' and 'imagined' drama.

The unusual thing about Mumford's position is that his 'real' drama preserves an element, namely, aesthetic properties as an intrinsic feature, that one might normally be likely to cite in elaborating what it is for something to be a case of his 'imagined' drama. He needs to be able to keep aesthetic properties as intrinsic to both 'real' and 'imagined' drama in order to succeed in his argumentative strategy. To locate something called 'drama' in sport that does not have an aesthetic dimension in an intrinsic sense is of no help in relation to achieving his goal of trying to demonstrate a closer affinity between sport and art than Best would countenance. Neither is it any help with regard the related project of elaborating an account of purism in sport spectatorship as focussing on aesthetic properties of sport qua sport. If the only connection between drama in sport and drama in the theatre is the word 'drama', but in each case the word 'drama' means something different to the extent that talk of drama in sport does not entitle us to infer sport has an intrinsic aesthetic dimension, then Mumford's project will not work. The problem then, is that in order to answer the question about the difference between 'real' and 'imagined' drama, without begging the question, it seems necessary to elaborate substantive differences between the two, and there seems to be nothing in the elaboration we might give of Mumford's 'real' drama that warrants the thought that the aesthetic is fundamental to it, and lots in the elaboration of what he calls 'imagined' drama that warrants the thought that it is something that fundamentally has an aesthetic dimension, such that to consider it independently of its aesthetic dimension is not to consider it at all.

As noted, Mumford doesn't really help us much with the question about the difference between 'real' and 'imagined' drama. He seems to take the former to be events outside of the arts that we might describe as 'dramatic', and the latter as drama in the arts. The worry is that in the case of the former, while we might describe such events as 'dramatic', there is no reason to infer from that that they are instances of intrinsically aesthetic enterprises, which is to say that we have other uses of words such as 'drama' and 'dramatic'. A related worry is that in the latter case, there is more than one use of the terms 'drama', 'dramatic' etc. because there are significant differences between talk of 'drama' in the theatre, film and television on the one hand, and talk of 'drama' in, for example, music or painting. We don't tend to describe drama in the theatre, film or television as 'dramatic' because it 
generates some kind of pleonasm, but we do describe some music as 'dramatic' or some paintings as 'dramatic'.

Put simply, what Mumford calls 'real drama' doesn't look like it has a connection to the aesthetic in the way that his 'imagined drama' has. If that is the case, then Mumford's identification of 'real drama' in sport could contribute nothing to his claim that the drama in sport constitutes an important aesthetic property of sport, and therefore is able to form a basis, among other things, of the purist's aesthetic appreciation of sport.

The drama argument, and, more specifically, Mumford's rejection of it, is, therefore, central to the distinction between partisan and purist ways of watching sport and to the view of sport spectatorship articulated and defended by Mumford. Best (1978), however, did not develop the drama argument in great detail (little more than two pages, 1978: 117-19). That was scarcely a problem prior to Mumford's work on sport spectatorship, but now it seems necessary to look at the drama argument again. I have considered Mumford's rejection of the drama argument elsewhere (Culbertson, 2017), but here I will look in more detail at the substance of Best's argument for the purpose of making clear the degree to which the drama argument really does seem to present insurmountable problems for a central strand of Mumford's position on sport spectatorship. The paper makes three main contributions: it offers an elaboration and development of Best's argument by viewing it in light of some elements of Wittgenstein's work. In doing that, it also offers reasons to worry about Mumford's move in rejecting the drama argument, and finally, it suggests ways in which, if those worries are justified, Mumford's wider account of sport spectatorship and the relationship between sport and art seems problematic.

The paper will begin by outlining Mumford's argument $(\S 2)$ before locating the nature of Best's argument in an elaboration of Philosophical Investigations $\S 43$ (hereafter $P I$ ) and Wittgenstein's wider employment of the concepts of a languagegame and a form of life (§3). It will then look closely at different uses of the term 'dramatic' (§4) before elaborating Best's description of the conventions of drama in brief discussion of uses of the terms 'tragic', 'illusion' and 'emotion' and their cognates, while considering the implications of those for Mumford's (2012: 49ff.) distinction between what he calls 'real and imagined drama' (§5). The paper will then stress some important differences between sport and drama (§6), before concluding with some remarks on how we might understand descriptions of sport as being dramatic, and on the origins of the confusion in relation to this issue as being in the construction of philosophical theories (§7).

\section{Mumford on drama and sport}

I have suggested elsewhere (Culbertson, 2017) that Mumford's argument on the issue of drama and sport (see Mumford 2012: 49-56, but also 22 and 47) is not the easiest thing to discern because it consists largely of examples with no clear statement of what he would like us to take from the examples. That is not a criticism; such an approach leaves space for the reader to think the matter through 
for him- or herself, but that style of philosophical writing tends not to be deemed appropriate for most journal articles, so something a little clearer is required. As a consequence, I attempted (Culbertson, 2017: 3-5) to bring the argument to light largely by quotation. The idea being that laying various things that Mumford says on the subject side-by-side brings out his argument, even if, to some extent, it is necessary to take what he says and then rationally reconstruct the rest by working out what he is logically committed to on the basis of what he directly states. I repeat that process here briefly because doing so is necessary to help, a little later, in clarifying what the differences between Mumford and Best consist in, thereby clarifying the issue at stake.

Mumford (2012: 50) says that '[s]port contains what looks for all the world like drama', and that ' $[r]$ ather like a theatre play, ... there can be many plots, sub-plots and surprises along the way before we get to the end point'. He asks: 'If a play is art, shouldn't sport also be considered so for containing an equal measure of drama?' In an important step, he also speculates whether 'it might be supposed that the drama [in sport] is all the more intense because it is unscripted and real' (Mumford, 2012: 50).

Unlike Best (1978), Mumford doesn't think that the claim that sport can be dramatic involves a different use of the word 'dramatic' from that which is common in relation to the theatre, film or television drama, but Mumford doesn't directly address the various elements of Best's argument. On the contrary, he gives various examples of what he takes to be similarities between sport and drama, implying that from those we should infer certain conclusions. Those examples are as follows: ${ }^{1}$

i. Sport can be considered scripted theatre because ' $[\mathrm{t}]$ here are certain script-like elements in the rules. They tell us how, in abstract terms, a sporting event begins and how it ends and a good deal about the sorts of things that could happen in between' (Mumford, 2012: 51).

ii. Sportspersons can be seen as actors playing an assigned role ('In a perfectly reasonable sense, sport sees an interplay of characters acting out roles', Mumford, 2012: 56).

iii. Players and athletes can be injured or defeated, but the same is true of actors, 'who might sustain accidental injury and find something akin to defeat in a bad performance' (Mumford, 2012: 56).

iv. As with the character in a play who falls in love with the leading lady (but not the actor), '[I]t is the sportsperson in their character that wins or loses the match' (Mumford, 2012: 56).

v. Outside of sport athletes and players may judge the successes and failures of their lives by other (non-sporting) criteria.

His conclusions seem to involve the following: 
a. There is no sharp division between 'real' drama in sport and 'imaginary' drama in the theatre.

b. There are, therefore, 'some closer parallels between art and sport' (Mumford, 2012: 56); closer than Best accepts.

c. 'Drama can be found in other areas of life, outside the arts' (Mumford, 2012: 56).

d. 'Even if the drama of sport were to be indistinguishable in nature from drama in the arts, this would not make sport art' (Mumford, 2012: 56).

More widely, the point seems to be that by, as he sees it, showing that sport and art are closer than Best would have us think, and that there is no clear distinction between 'real' and 'imaginary' drama, he clarifies the focus of the purist's approach to watching sport by locating a clear aesthetic dimension to sport. By showing that there is always something for the purist to appreciate, the purist's way of watching sport is defended against the accusation that to watch sport with an emphasis on aesthetic features is often not to watch the sport (qua that sport) at all (Culbertson, 2016: 185ff. Cf. McFee, 2004: 130-32 on the notion of a 'sport-shaped hole' and McFee, 2015: 123ff.).

\section{3. 'For a large class of cases ... though not for all'}

One of the central considerations at issue in this paper is the question of how we might establish whether the fact that we can use the same word(s) in different contexts ${ }^{2}$ means that we can infer the same things in each case. That is often phrased as 'whether they mean the same thing in each case', but an important part of the argument here is that words or sentences mean the same thing when used in two cases if and only if the same inferences can be made. What that means is that when we ask about whether certain words or sentences mean the same thing in two cases, the answer will depend on our concern in asking the question. For some purposes, there may be no difference, and for others there may be a difference, and what will determine whether there is a difference or not is whether taking them to have the same meaning would lead one to inferences that were incorrect or inappropriate. Where the relevant inferences that suit one's purpose at a given time would be correct or appropriate, the words or sentences being asked about do have the same meaning for the purpose at hand, but where taking them to have the same meaning leads to incorrect or inappropriate inferences, they do not have the same meaning for the purpose at hand.

There is no general answer to the question about whether they have the same meaning in two cases if 'general' here means independent of consideration of, or specification of, any purpose in asking the question (as opposed to asking, generally, whether two words can have the same meaning, which is a different question entirely). There can be no answer to such a context-less question because the meaning of the question depends on the specifics of the cases one is asking about 
and one's purpose in asking the question, which includes consideration of what one might be looking to infer from the words or sentences once one has an answer to one's question about whether they have the same meaning in two different cases. All of that is important, because that is the issue at the heart of the difference between Best's view and that of Mumford on the use of the terms 'drama', 'dramatic' etc. in relation to the theatre, film and television on the one hand and sport on the other. We should not be misled by the fact that Mumford doesn't view the matter as being about the use of words, but rather about, as it were, what someone might call 'drama itself' or 'the nature of drama'. The implied contrast is between calling something 'drama' and it being drama, but if someone calls something drama and it is not, then they have used the word incorrectly in that context. If we can, appropriately, call something drama, then it is.

The matter cannot be profitably addressed without considering the contexts in which terms such as 'drama' are used, both generally (sport, the theatre, etc.) and particularly on specific occasions of use. What constitutes use depends on both such types of context, and so in cases where asking about meaning amounts to asking about use (which is the situation here), we must be concerned with the way words are employed in ways that are interwoven with the activities of human beings, both specifically on particular occasions and more generally in different types of activity, such as that found in the theatre on the one hand, and sport generally, or specific sports on the other. That is one reason why Wittgenstein can help us here. His introduction of the notion of a language-game, his specific understanding of use in relation to language as interwoven in the activities of human beings, and, to a lesser extent, his concept of a form of life, are all helpful in the task of making sense of his suggestion that often, but not always, when asking about meaning it is profitable to consider how words and sentences are being used. Making sense of that will help in addressing the differences between Best and Mumford because those differences are over whether the fact that we can describe events in sport as 'dramatic', or say that there was great 'drama' in those events, should be understood as using 'dramatic' and 'drama' in the same ways as we usually do in relation to drama in the theatre, film and television, such that the inferences we can draw from the fact that we can say such things in both sets of circumstances are the same. In short, is Mumford entitled to argue that the fact we can say such things about sport shows that there is drama in sport, and that, as a consequence, there must be an aesthetic dimension inherent to sport because there is an aesthetic dimension inherent to drama? Mumford thinks that such an argument helps locate the focus of the purist's way of watching sport and that it also shows that sport and art have a closer affinity than we have tended to think since Best's attack on the idea that sport could be art. ${ }^{3}$

The other reason consideration of some of Wittgenstein's work can help us here is that Best was significantly influenced by Wittgenstein and if one is puzzled by Best's position (by what the position actually is), then looking to Wittgenstein can help to dissolve that puzzlement. It is also worth noting that while Mumford is certainly not influenced by Wittgenstein, he does, however, subscribe to a form of contextualism about meaning (Anjum and Mumford, 2011), so one might see this paper as picking up that thread and exploring some of the terrain on the route that following those 
contextual considerations takes us. The thought being that Mumford shouldn't end up where he does if he really wants to take the contextual factors seriously, and if he doesn't want to take those factors seriously, then we have a clash of two philosophical worlds in the differences between Best and Mumford on these matters, and the paper attempts to provide some reasons to prefer something like Best's view. ${ }^{4}$

In an often-misunderstood passage ( $P / \S 43)$, Wittgenstein reminds us that '[f]or a large class of cases of the employment of the word "meaning" - though not for all this word can be explained in this way: the meaning of a word is its use in the language'. The common misunderstanding comes from ignoring the qualifications and reducing the remark to constituting a 'theory' of meaning as use. It is nothing of the kind, but it is an important observation about the significance of paying attention to the use to which words are put, because in many cases, although not all, differences in use constitute (rather than reflect) differences in meaning. ${ }^{5} \mathrm{Baz}$ (2012: 2) stresses the fact that 'use' here is not to be contrasted with mentioning words, but rather with 'letting them idle, or failing to do any (real) work with them' (cf. PI $\S 132$ ). Putting words in a sentence is 'not yet a move in [a] language-game' (PI §22) because 'the speaking of language is part of an activity, or of a form of life' ( $P I \S 23)$. Likewise, Wittgenstein ( $P I$ §26) stresses that we can call naming something 'preparation for the use of a word', but the important question is 'What is it a preparation for?' The connection to Austin's concern with the things we do with words is clear (cf. Austin, 1975).

This helps us see that much of the time (but not always) the expression 'the meaning of a word' is equivalent to the expression 'the use of a word' ( $P I \S 560$, which refers to The Big Typescript, hereafter BT, p. 29, also see Hacker, 2013: 126). Asking about the meaning of a word, therefore, is not to ask about some hidden essence ( $P I$ §92), but rather is often to ask about how a word is being used or is to be used in a specific context. Of course, it also needn't be the case that in explaining the meaning of a word we have to describe its use. Pointing to the bearer of a name ( $P I \S 43[\mathrm{~b}])$ is one such example, as is the approach referred to by Wisdom (1965: 69-70) as 'the mother's method' of explaining what a greyhound is to a child. Rather than saying 'A greyhound is a dog of a certain sort', which might be met with the question 'but what sort?', and that may lead to the reply 'a greyhound is a dog in which the power to weight ratio...', which Wisdom calls 'the father's method', one might give examples, both of greyhounds, and of dogs that might be confused for greyhounds, as a means of helping the child see what does and does not count as a greyhound. Compare this to PI $\S 66$ which describes some of the range of things we call 'games', and so some examples that might be given as objects of comparison in helping someone develop an understanding of games. Of course, we might also say that what we would be helping someone develop in such cases is an understanding of the uses to which we put the word 'games', and therefore possession of the concept. We might also say that much of what it is to possess a concept is to know how to go on in relevant language-games, employing the concept-words in question (in this case 'drama' etc.). 
Wittgenstein used the expression 'language-game' for a family of related things as a means of assisting us to break free of the grip of a picture of language as operating according to a calculus of definite rules (a picture that he had contributed to articulating in $T L P$ ). Many of the things he called 'language-games' involved inventing primitive uses of language, such as (i) primitive and incomplete elements of ways of operating with language that might be the kind of thing a child learns in the early stages of learning a language, (ii) primitive but complete 'languages', (iii) models to compare to actual uses of language for the purpose of showing defects in a particular philosophical position, or (iv) primitive, invented, language-games that are supposed to be played in contexts other than those in which we employ our language-games (see Baker and Hacker, 2009a: 59-61). Such language-games have a methodological function in that they serve as objects of comparison ( $P / \S 130)$ that can be employed to clarify features of our uses of language through identification of similarities and dissimilarities.

Importantly, Wittgenstein also uses the expression 'language-game' for fragments of our actual uses of language, in other words, uses that are not invented or simplified. It is that use of the expression 'language-games' that is particularly useful in the context at hand. Such language games may involve uses of particular words, such as 'game' (PI §71), 'read' (PI §156), or 'pain' (PI §300), groups of words that have interconnected uses, such as 'proposition', 'language', 'thought', and 'world' ( $P I$ $\S 96)$. Equally, he identifies language games around different linguistic activities, such as a long list of examples in PI §23, including, inter alia, 'giving orders, and acting on them', 'describing an object by its appearance, or by its measurements', 'constructing an object from a description (a drawing), 'reporting an event', speculating about the event', 'requesting, thanking, cursing, greeting, praying'. Elsewhere, he gives the examples of lying ( $P$ I §249), telling ( $P I \S 363)$, use of 'I dreamt ...' followed by a dream narrative (PPF §52), predicting by induction ( $P I \S 630$ ) (see Baker and Hacker, 2009a: 63 for further examples and discussion).

How does the notion of a language-game help in this context? The analogy with a game focusses our attention on the activities with which our uses of language are interwoven, rather than on the search for a hidden set of 'strict and clear rules for the logical construction of a proposition' ( $P / \S 102)$, which are so often thought to be 'pure and clear-cut' ( $P I \S 105)$ and constitute an ideal ( $P I \S 103)$, 'the incomparable essence of language' ( $P / \S 97)$. Such 'crystalline purity of logic' was 'a requirement' ( $P I$ $\S 107$, cf. PI §97) imposed by a picture of language that had gripped us, rather than something that we discovered. When we look at our actual uses of language we find that the discrepancy between the ideal and the motley of different language-games, is too great to sustain the myth of that ideal. It is for that reason that we have to return 'to the rough ground' ( $P I$ \$107) of our actual uses of language in particular contexts on specific occasions of use interwoven in activities. Doing so places emphasis on 'the logical diversity and the multiplicity of our speech activities' (Baker and Hacker, 2009a: 64) and the interconnections between our use of words and our lives and the activities in which we engage as part of those lives, along with the normative (rule-governed) nature of those activities and the uses of language which make sense to us when interwoven in those activities, and often fail to make sense 
when abstracted from the context that forms their natural home, often leading to nonsense or confusion when attempts are made to employ them in different contexts as if the fact that the words are the same should mean that what gets said (and done by uttering them) is the same, regardless of the change in context of use.

It is in this interweaving of uses of language with the activities of our lives in ways that have normative significance that links the notions of language-games, use and form of life. It is important, however, not to try to make too much of the notion of a form of life. As Hacker (20015: 18) correctly observes, "the expression "form of life" plays a very small role in Wittgenstein's later philosophy. No aura or mystique should be allowed to attach itself to his notion of a form of life. In itself it is of no great moment'. While the concept itself may be of no great moment, the wider way of thinking of which it is a part certainly is. Hacker (2015: 18-19) describes that wider way of thinking as:

the ethnological conception of language as a form of activity embedded in the ways of living of a language-using community. That activity is normative, i.e. rule-governed - but not in the manner of a calculus; rather in the manner of a game. The rules for the use of words and symbols are given by explanations of meaning, including definitions (no matter whether analytic definition, ostensive explanations, contextual paraphrastic definitions, or family-resemblance explanations). But for there to be rules at all, there must be agreed ways of employing-rule formulations as guides for the application of the expressions the meaning of which they explain, and as justifications of the applications. What welds a rule to its applications (its extension) is the practice of going by it. This is an agreement in a form of life, involving consensus concerning what counts as applying the rule correctly. That in turn demands a widespread if indeterminate consensus in judgements.

Wittgenstein stresses that the agreement in judgements to which Hacker refers is not agreement in opinions, but rather agreement in form of life (PI 241-42). There is variety to our forms of life. There are many of them, but there is no clear distinction between them such that individuation is possible independently of context and a concern in asking about what counts as a form of life. Hacker (2015: 11) notes that '[d]ifferent educations, interests and concerns, languages, different human relations and relations to nature and the world constitute distinct forms of life', but what will count as different depends on the circumstances and concern of our asking about whether something is the same or different. The concept has use because it helps emphasise the interwoven or embedded nature of language within the ways we live, such that language is partly constitutive of those ways of living. Wittgenstein draws our attention to the way in which becoming someone who has that, or perhaps better, those, forms of life, is intimately wrapped up with coming to possess concepts and developing a mastery of inter-related language-games in all their normative, occasion-sensitive, complexity.

Best's argument is about the use to which terms such as 'dramatic' and 'tragic' are put in different contexts. When used in sporting contexts, or in everyday contexts in 
relation to the events of people's lives, they are not usually used in a context in which the conventions of the theatre, film or television drama apply, and they therefore mean something significantly different. The most significant implication of that for the conclusion Mumford draws is that uses of 'dramatic' and 'tragic' in relation to sport do not signify an aesthetic dimension to sport because they are not being used in a context in which the aesthetic is central to the conventions of the relevant activity (as they are in the theatre, film or television drama). Rather, in purposive sports in particular, they are being used in a context in which the means by which victory is achieved need have no aesthetic value as long as it is within the rules of the sport. It is this difference in the prevailing conventions of the respective sets of activities (in sport on the one hand, and drama in the theatre, film and television on the other) that shows most clearly that in relation to sport 'dramatic' and 'tragic' are used figuratively.

To show that Best is right about that, and to help demonstrate that Mumford's position is, therefore, untenable, the next section will look at uses of 'dramatic' and its cognates in various different contexts. That will then be followed by a section that looks at the importance Best places on the notion of the conventions that apply in the different contexts of the theatre on the one hand and sport on the other. Those different conventions reflect differences of education, 'interests and concerns, languages, different human relations and relations to nature and the world' that 'constitute distinct forms of life' (Hacker, 2015: 11), and as such make a significant difference to the context in which the relevant uses of language should be understood.

\section{Uses of 'dramatic' and its cognates}

It will be helpful to begin by saying a little about the strategy and the method employed here. Doing so will not only clarify what follows, but also show the connection between the discussion of language-games, uses of language and forms of life in the previous section and the way in which this section and the next proceed.

What follows could appear to some as an unconnected series of platitudinous observations about the things people sometimes say, or, perhaps worse, as a number of half-articulated, but never quite clearly stated, arguments that could do with tidying up into formal inferences. It is neither, and it cannot be understood if thought of as such. The method here and in the next section is intimately connected to the way of thinking outlined in the section above and to the conception of philosophy that motivates that way of thinking. For Wittgenstein (PI §126),

[p]hilosophy just puts everything before us, and neither explains nor deduces anything. - Since everything lies open to view, there is nothing to explain. For whatever may be hidden is of no interest to us. The name "philosophy" might also be given to what is possible before all new discoveries and inventions. ${ }^{6}$ 
What is needed here is not an explanation, but a description of elements of the language-games that we play embedded in various contexts within forms of life. The point of that is to show that what can be said by using certain words in some particular context cannot be said by using those same words in certain other contexts, and that it is such a confusion that lies at the heart of the difference between Best's view and Mumford's view on the issue of drama and sport. For Wittgenstein, '[a] philosophical problem has the form: "I don't know my way about"' ( $P I \S 123)$. Under such circumstances it is easy to get lost and one way of making sense of the confusion in Mumford's position is to see it as the result of getting lost as a consequence of not knowing our way about when confronted with uses of language in quite different contexts that appear the same (they use the same or similar words). Mumford concludes that the contexts are more alike than we have tended to think because the words we use are the same or similar, whereas Best, like Wittgenstein, wants to draw attention to the fact that as the contexts are different in a way that is normatively significant, the use of words cannot be the same.

The primary reason that we fail to know our way about in the sense Wittgenstein means is that we struggle to find 'an overview of the use of our words' (PI §122). The employment of descriptions of our actual language-games by drawing to attention various things that we can say, along with some indication of the contexts in which we can say them, such that uttering those words in those circumstances (and also often while engaged in some specified activity) makes sense and constitutes doing something with words in the manner referred to by Baz (2012) as outlined above. That is what it is to use words, rather than letting them idle. Equally, such an approach also enables us to identify examples of situations in which the words we utter do not succeed, in a specified context, in saying something that makes sense, which is not to say that the same words wouldn't make sense if uttered in a different context, where 'context' includes, but is not exhausted by, the activity with which the specified use of words is interwoven.

It is important to understand that Best's argument is not about how people tend to use words - it is not armchair corpus linguistics. It cannot, therefore, be refuted by accounts of the history of the use of 'drama' and related terms. Rather, the argument is about the logic of the concepts. In other words, it is about what follows from (i.e. the inferential possibilities that arise from) the use of a word in a particular context, on a specific, occasion-sensitive, understanding of what is said on that occasion of utterance or use. ${ }^{7}$ Another common misunderstanding of the approach adopted by Best is that it is an exercise in policing our use of language, but it is nothing of the kind. The approach amounts to something like saying the following: if you are going to use those words, in that way, in those circumstances, as part of that kind of interaction, speaking to so-and-so, when those things have just happened, and saying that will lead to the following, then what you will say is such-and-such, and what follows from saying that is .... Drawing that to the attention of a competent speaker of the language who possesses the relevant concepts should lead to that person giving up what he or she otherwise wished to claim because it will be apparent that it is logically inconsistent to hold that view under those 
circumstances. ${ }^{8}$ It does not involve asserting that given words can only be used in given ways and can only be used to say certain things. There is no dogmatism in Best's approach; the force of the observation is derived from clarification of the use made by the person to whom that clarification is directed, not by some use imposed by Best. With those points in mind, the following observations about uses of 'drama', 'dramatic' etc. should be seen as reminders 'for a particular purpose' (PI §127), such that those reminders should be considered in specific contexts in thinking through the issues considered here.

i. 'Don't be so dramatic!' - used when someone is making rather too much of a situation, usually in a negative sense. It is related to 'There's no need to make a song and dance about it'. The metaphor in both cases is theatrical and draws on the idea that acting in the theatre is conspicuously a performance, and is, in that sense, quite clearly exaggerated. The same idea is at the root of the expression 'There's no need to make a production of it', said when chastising someone for making rather too much of performing some task that should be relatively straightforward. Uses such as these are, therefore, metaphorical and allude to the theatre, but they do not imply that there is anything in the behaviour being criticised that is worthy of aesthetic or artistic appreciation. Quite the contrary, these are expressions used to criticise behaviour that is, in the specific context, quite inappropriately reminiscent of drama in the theatre.

ii. 'That was the most dramatic ending to a football match I've ever seen!' likely to be used in a context in which there was uncertainty until the very end of the match as to who was going to win. It may, however, also be said in a situation in which the match was eventful. It needn't be the case that an eventful match must be one in which the result remains uncertain until the end; a match in which fights between players occur regularly, players are sent off, a manager is sent to the stands by the referee etc. is quite possible where it is clear who is going to win. In both matches where the result is uncertain until the very end, and those that are eventful, or indeed in eventful matches where the result is uncertain until the final seconds, there is nothing to warrant thinking of use of 'drama' as the same as that in the arts. The uncertainty as to the result is not creatively orchestrated. There have been no artistic decisions made to heighten the suspense or the tension, nor are the fights and sendings-off the result of creative decisions; they are just the result of anger. The temptation, to which Mumford succumbs, is to think of such matches as containing real drama, and of drama in the arts as an imaginary enactment of real or possible drama. That is, however, to misunderstand the figurative use of 'drama', 'dramatic' etc. for the standard use. It is central to what gets said, in calling something 'drama', in its standard use, that it is imaginary. Bearing in mind Austin's (1979: 62-3) worries about the expression 'part of the meaning of the word $x^{\prime}$, that expression has been avoided, but it is unproblematic if one recognises that using such an expression is just to say that, in explaining the meaning of the word 'drama' in its standard use, one would be perfectly correct in stressing the role of the imaginary in drama. If someone objects to the priority of taking talk of drama in the theatre as the standard use, then we can give that up because it plays no part in establishing the point, which is that the two uses (in the theatre and in sport) are 
relevantly different in relation to the issue of when it would be appropriate to infer an aesthetic dimension, and so the same inferences are not warranted in each kind of case (which is Mumford's error). It doesn't actually matter which we take as the standard use and which the figurative. All that matters is that they are different in important ways that mean that one can't infer an intrinsic aesthetic dimension to sport on the basis of the fact that we can, quite appropriately, but on one specific understanding of the word, describe (some) sport as 'dramatic'.

iii. [On reporting that one witnessed two people fighting in the street] 'It was really dramatic!' There's nothing in this use that implies aesthetic appreciation. If someone finds two men fighting in the street aesthetically pleasing, we might, with some justification, think that they should be locked up along with the two men!

Outside theatre, film, television etc. (in ordinary life) we often describe things (car chases, fights etc.) as being 'dramatic' that are not what we would regard as good drama in the sense we use that term in the theatre. Would a fight where we had no knowledge of the protagonists, and were not subsequently to be given any, make a good play or film? It seems likely that the absence of any narrative supplied for us would make it much harder for us prefer the triumph of one person over another, say, the triumph of good over evil. In relation to suspense in film, Carroll (2008: 160) argues that '... suspense is arguably an emotion with two criteria - improbability and the desire that the good shall triumph' ${ }^{9} \mathrm{~A}$ desire to see the good triumph requires the ability to distinguish between the participants in suitable ways that one cannot do in the case of a street fight between two strangers. The point being that not everything that we might, in one sense (i.e. that outside the theatre etc.), appropriately describe as being 'dramatic' is something that we would regard as good drama (in the theatre etc.). Not everything that is dramatic is drama. Indeed, we often don't describe drama as being 'dramatic'; it would be an odd response, when asked about a performance of King Lear, to say 'It was very dramatic'. Such a response would often betray one's lack of appreciation of the performance as an art form. It might be better to say that our uses of 'drama' and 'dramatic' show great variety and often things we describe as 'dramatic' are not things we would call 'drama' in the sense of those things that we find in the theatre, film and television, and often we don't describe drama in the theatre, film or television as 'dramatic'. Drama in the theatre, film or television is not dramatic in the sense in which events elsewhere that we would describe as 'dramatic' are said to be so, and those events are not drama in the sense in which activities in the theatre, film and television are said to be such.

Someone might think that to make such an observation speaks in favour of the idea that sport contains drama in the sense in which we find drama in a film (and in a play or television drama) because we can differentiate between the participants in sport, and so can favour a particular outcome. That much is true, but that was not all that was identified as necessary for suspense and drama. Admittedly, sometimes we might feel that the criterion of improbability could be met in sporting cases (the victory of the underdog, the strange bounce of the ball etc.), but any identification of good and evil will usually be based more on one's allegiance than any real 
understanding one has of the participants. There may, of course, be exceptions to that, but in such cases the identification of good and evil (and often 'evil' will be an exaggeration) will be based on knowledge of the players or athletes, and not on characters, as it is in a play, film or television drama.

Someone might think that there are characters in wrestling and sometimes in boxing. That is true, but it is also the case that in such situations the degree to which it is true is also the degree to which we would want to question whether the activity concerned is sport or some kind of show. The case of Muhammad Ali is far too complicated to discuss here, but it is sufficient to warn against making too many assumptions about being able to make a clear distinction between what was show (and the character) and what was the man.

In cases of improvisational theatre there may be a rough structure, but no predetermined outcome, but those are precisely the cases where we wouldn't know in advance whether there would be anything of positive aesthetic value. The same is true, to a limited extent, in jazz, where the degree of improvisation influences the degree to which we could know in advance whether the music is likely to be of positive aesthetic value. This is not to conflate positive aesthetic value with aesthetic appreciation or evaluation. Mumford seeks to locate positive aesthetic value in sport. His purist doesn't go to a football match to enjoy evaluating the play as ugly.

iv. 'He did it for dramatic effect'. The origin of 'dramatic effect' is the theatre, ${ }^{10}$ where it refers to things such as lighting, music, staging or costumes that are designed to attract the attention of the audience in such a way that enhances the art-form, but it has an idiomatic use in everyday speech where it is used in contexts where someone did something in an exaggerated manner for the purpose of achieving a highly visible effect or to attract attention, rather than doing it because it achieved any other useful purpose. In the context of the theatre, dramatic effects are part of the art and are properly judged from an aesthetic perspective. The idiomatic use is idiomatic precisely because it isn't properly evaluable from an aesthetic perspective. If someone really did do something for dramatic effect in that sense, then it was done to attract attention, but not in an artistic context, and therefore not for the purpose of enhancing an art-form. Sometimes, although not always, it may be connected to melodrama, but again, that expression has a use in the theatre and an alternative use that is not connected to any art-form, but is, rather, related to exaggerated emotions.

v. Mumford's expression 'real drama'. It is central to what gets said, in calling something 'drama' in its standard use, that it is not real, so to talk of 'real drama' is like talking of a 'real unicorn', 'real fairy' or 'real phoenix'. Such expressions are oxymorons where 'real' does not qualify the term of which it is predicated, but rather renders the whole expression meaningless. If we appreciate that in explaining the meaning of 'unicorn', 'fairy' or 'phoenix' one might, rightly, use terms such as 'mythical', and therefore also 'unreal', then the expressions formed by placing 'real' before them amount to something that means 'real unreal', which is meaningless. Use of 'real' in these contexts is not like use of the term in 'real duck', where 
something is being predicated of the duck, which draws a meaningful contrast, such as that it isn't a toy, dummy, drawing etc. (cf. Austin, 1962: 67-70). Of course, we can have toy unicorns and drawings of unicorns (although perhaps not dummy unicorns, as 'dummy' implies that the thing of which it is a dummy exists), but unicorns do not exist, so while we do have perfectly good uses for the expression 'real unicorn(s)' ('There is no such thing as a real unicorn', 'There are no real unicorns'), those are only meaningful insofar as they are negative in nature. Positive uses of 'real unicorn' ('That is a real unicorn') are meaningless, so 'real unicorn' can't be used to draw the same kind of contrast as 'real duck' because there are such things as real ducks, but not real unicorns. To put the matter another way, we have positive uses for sentences containing 'real duck', but not for those containing 'real unicorn'.

It's important to recognise, however, that to put it that way ('There are such things as ...') could easily mislead because the important thing is not whether there are ducks in the world and no unicorns, but rather that it follows of calling something a 'unicorn' that it is a mythical creature, and therefore could not possibly exist. Unicorns are not like dinosaurs in that respect. There are no longer any dinosaurs in the world, but there were once, there are still related creatures, and (perhaps) there could be dinosaurs again as a result of a very long process of evolution, or (highly unlikely) by cloning from dinosaur DNA. The thing to stress, however, is not that dinosaurs and unicorns differ in relation to whether they have existed in the past, but that the meaning of 'dinosaur' and the meaning of 'unicorn' are distinctly different in that one no longer exists and the other is mythical. So if someone bred what they called a 'unicorn', it would either be a horse with a horn on its head or something other than a horse, but not a unicorn (even if it was called that). It couldn't be a unicorn (in the conventional sense in which we use that term) because it follows of calling something a 'unicorn' that it is mythical (cf. Krike, 1980: 24 and 156-58, Dummett, 1993: 327-48, particularly 341-43, and Harman et al., 1974). ${ }^{11}$

Equally, it follows of calling something 'drama', in the conventional sense in which we use that term, that it is not real, so to talk of 'real drama' is, as with 'real unicorn', 'real fairy', 'real phoenix' etc., to talk of the real unreal, which is meaningless. Unlike 'real unicorn', however, it is perfectly meaningful to talk of real events that we describe as dramatic, but in describing them that way we do not predicate of them aesthetic properties, but rather, depending on the case, that the outcome was uncertain, there was tension, they were frightening (e.g. a fight) etc.

vi. Dramatic music. Music is frequently described as 'dramatic', but although it is an art-form, it doesn't seem to be an example of the standard use of 'drama' with which Best contrasts talk of drama in sport. Someone might think that as music is an art-form, yet seems to be a different art-form from drama in the theatre, film and television (although those may contain music), then we have found an art-form that involves a different use of 'drama' from that which Best stresses, but which does have aesthetic properties. Finding such a case may be thought to undermine Best's argument and preserve Mumford's claim that real drama in sport provides an aesthetic dimension to sport spectatorship where the aesthetic properties are of the sport, not of inessential features such as the movement of bodies or projectiles. 
That, however, would be to fail to see that dramatic music invokes a sense of tension, suspense and perhaps certain emotions; as an art-form it is composed (i.e. is the result of a creative process) in order to invoke a sense of drama. If music is dramatic by accident, say because it was generated randomly by a computer, then it isn't an art-form, or, at least, its being dramatic isn't an artistic property, and if it is an art-form, then we should be able to tell some story about the intention of the artist in which, if the fact the music is dramatic is to be regarded as an artistic property, its being so must have been intentional at least in the sense that the artist chose not to change it, and perhaps even in the sense that he or she set out to compose dramatic music. But what is it for music to be dramatic? Well, we could give technical answers to that question in terms of the postponement of harmonic resolution, certain uses of dynamics or dissonance etc. Equally, we could, in certain cases, give an explanation in terms of the interplay between the music and the events depicted in an opera, a play, a film or a television drama, or indeed between the music and the acting in such cases. These seem to be two different categories of case. In the latter set of cases the music seems to be closely connected to the activities that constitute drama in the conventional sense, whereas in the first type of case the music itself invokes a sense of drama. That is not to say that the music in the first type of case is dramatic and in the second type of case it isn't in itself dramatic, but somehow becomes dramatic when used in the context of 'proper' drama.

To put the matter as bluntly as saying that art-drama is choreographed and dramatic real events are not would leave too much unqualified for such an observation to go unchallenged, but that is not too far off the mark, although things are a little more complicated than that. Certainly, dramatic real events are not choreographed, even if, for example, in sport, things are set up in certain ways that might bring a close finish or some such thing that we would describe as 'dramatic'. The important word there is 'might'. The part that is a little more complicated is the thought that artdrama presupposes intention and planning. It does, but in a rather loose sense, namely, that the decision has not been made to change anything. In the case of a painting that is related to deciding when the painting is finished and not subsequently deciding to do any further work on it to alter it, and film and television drama is similar in that regard. In the case of drama in the theatre and other live performing arts the equivalent of deciding not to change anything is a little different because one can't make changes to a given live performance. One could alter something the following night during a different performance, but in any single performance that which was not intended would often be thought to be a mistake by the performers, director etc., even if the audience could not recognise it as such. It's not quite as simple as that though because sometimes the unintentional is thought to be good. For example, a musician engaged in improvisation does not work out in advance everything that he or she does, otherwise it would not be improvisation. Nonetheless, there are sometimes things that the musician would rather not have done and sometimes things he or she is rather glad to have done (which is just to say that it is possible to differentiate good from bad improvisation). All of that is to stress the difference between art-drama and dramatic events outside of an art-form, and that is related to the discussion of the conventions of drama in 
the next section, but it should also be understood as helping us to see that talk of 'art-drama' is not always helpful because dramatic music and dramatic paintings are art-forms we could describe as being 'dramatic', but we wouldn't refer to them as 'drama'. As the discussion of dramatic music here is designed to help show, what we say when we say that such things are 'dramatic' is not that they share some essential property with either drama in the theatre, film or television on the one hand, or with dramatic events outside the theatre, film or television on the other. We need to consider specific uses on particular occasions in given circumstances. We need, as it were, to look and see what differences and similarities there are between cases, otherwise we will end up with crude categorisations.

Drama just is drama - we don't normally talk about dramatic drama or un-dramatic drama. When we say that music is dramatic, we predicate something of the music. Equally, when we say that a sporting event was dramatic, we predicate something of the sporting event, and the same is true of a fight in the street. What we predicate of the music, sporting event and fight may differ in each type of case or between individual cases of each type, but the things that we predicate of them are all figurative uses of the term 'dramatic', and those figurative uses are derived from the standard use of the term 'drama' used as a noun for specific activities in the theatre and certain films and television programmes (again, if someone doesn't like the priority of one use over another here it can be given up; the point is that the uses are different, it is not that the designation of one use as standard plays any part in the argument). Dramatic events, music, painting etc. can be said to be 'dramatic' because they are like drama in certain ways, but not in others; they aren't drama and don't share the property of being dramatic with drama (only rarely, and in very specific circumstances, would we talk of dramatic drama), yet dramatic events, music and painting, share the property of being like drama in some way, but not necessarily in the same way.

Another difference here between drama and dramatic music is that dramatic music does not represent determinate circumstances, actions or statements; there are no propositions. Some examples might help make this point clear. The second movement of Dimitri Shostakovich's Symphony No. 10 in E Minor is sometimes regarded as a portrayal of one of Stalin's military parades, but there are no finite events portrayed; we couldn't listen to the music and say with any certainty precisely what took place at the parade. Equally, Ry Cooder's 1987 recording of Thirteen Question Method has a section where Cooder says 'And she said' followed by a passage of bottleneck guitar played in the treble. Cooder then says 'And he said' followed by a passage played in the bass, before the bass and the treble are intertwined as if they are a conversation between a man and a woman. We can have no idea, however, what the man and the woman are supposed to have said because nothing is actually said, certainly no determinate statements are made. What's more, Cooder can't know what the man and the woman say to each other, even if he invented an answer and said those words silently to himself as he was recording it. Finally, call and response, where the response is played by an instrument (even when we know what lyrics have been omitted) is not a determinate statement made in a musical language. 
The examples here are designed to show two things in particular, namely, the great variety of uses of terms such as 'dramatic', and the fact that different uses are relevantly different in relation to some inference that someone might wish to make. That is to say that what makes them different uses is precisely that they cannot support the same inferences in the circumstances at hand. Determining difference of use is, therefore, an occasion-sensitive matter. Those things are important because it is Mumford's failure to recognise them that seems to be at the root of the confusion in his position.

\section{The conventions of drama: tragedy, illusion and emotion}

It is possible to build on the observations in the section above by considering Best's employment of the notion of the conventions of drama. That is important because of the fact that it is connected to the description of uses of language above as to be understood occasion-sensitively and as interwoven with the specific activities of human beings, which are related to our various forms of life, or to the ways we live and the practices and activities in which we engage within different normative contexts. In drawing attention to the conventions of drama Best emphasises the role of those factors in helping us see the ways in which using the same words in different contexts can fail to constitute us saying the same thing. In considering the conventions of drama Best discusses three concepts that are related in various ways to drama, namely, tragedy, illusion and emotion. These should not be seen as essential features of drama, such that they form some kind of definition. Like the discussion of suspense above (another feature that Best could have discussed in relation to the conventions of drama) we are in the territory of 'family resemblances' ( $P I \S 67$, see also $\S \S 65-66$ ) rather than that of definitions in terms of necessary and conjointly sufficient conditions.

Best (1978: 118-19) identifies two uses of 'tragic' that are outside the conventions of drama (in the theatre), and therefore should not be confused with those uses of 'tragic' that are within the conventions of drama in the theatre. Those are:

i. Cases where the term is used in relation to, for example, a serious injury in sport. In such cases the player really is injured, and the equivalent in a play, film or television drama would be an actor being seriously injured during the play or during filming. That is distinctly different from a character being seriously injured in a play, film or television drama; in such cases the actor remains unharmed. This sense of the term does, of course, have a perfectly good use outside sport, but also outside the conventions of drama, such as when people are killed, seriously injured or suffer from serious illnesses. As a consequence, we might think of tragedy as different from drama in that we can make perfectly good sense of the idea that drama depicts tragedy, but not of the idea that drama depicts drama (as opposed to depicting the making of drama). That is just to say that while Mumford's notion of 'real' drama is a metaphorical use of 'drama' (although it is actually usually of 'dramatic') that should be understood as quite distinct from our most common everyday use of the term, we might think of 'tragic' as functioning rather differently - we might feel drawn to 
say that some things that happen to people really are tragic, and our use of the term within the conventions of the theatre designates a type or feature of drama that depicts 'real' tragedy.

ii. What Best (1978: 119) quite understandably calls 'the irritatingly prevalent but barbarously debased sense of the term' that we find in calling a failure on the part of an athlete, player or team to achieve an aim, and the resulting disappointment (including that experienced by spectators) a tragedy. The equivalent in relation to the theatre would be an actor failing to play a part well, his or her performance being badly received, or an actor failing to win a role that he or she dearly wanted. Best's warranted frustration over this use of 'tragic' reflects the fact that there is nothing tragic about it. That is brought into sharper focus if we consider what would be necessary to turn such cases into something that warrants being described as 'tragic', such as an actor committing suicide as a result. It is the suicide, and the suffering leading to it, along with the suffering of relatives and friends afterwards that is tragic, not the failure or disappointment.

Best (1978: 119) further develops the notion of the conventions of drama by pointing out that within drama the term 'illusion' has a different meaning from its common use outside the conventions of drama. When I experience an illusion outside of drama I really do think that the illusion is real, or at least it appears to be real. Best uses the example of a mirage, in the sense of an illusion, rather than the sense in which 'mirage' is sometimes used to mean a hallucination. If I see a mirage, I really do think that I see, for example, water in a desert where there is no water. In contrast, when I see someone killed in a play, I don't think that the actor has really been killed, or, if I do, I do not understand drama and the notion of a play. ${ }^{12}$ In the theatre there is a collective effort made to assist the audience in achieving a suspension of disbelief, but the whole thing is an exercise in imagination rather than in belief. Again, there is no equivalent convention in sport; one does not need to imagine the players as one does the characters in a play.

The conventions of art are also important in relation to confusion over the fact that one can experience emotion as a result of both sport and art - the confusion being that such an observation shows a connection between sport and art that in some way justifies the claim that sport is art, or, in Mumford's case, that sport and art are brought closer together by such an argument. Best (1978: 120) stresses that the intentional object (that towards which the emotion is directed) in art cannot be articulated independently of a grasp of the conventions of art, and that while the same is true of sport (the intentional object cannot be articulated independently of a grasp of the conventions of sport), the conventions of art and the conventions of sport differ in important ways, even in the case of aesthetic sports.

The activities into which uses of 'drama', 'dramatic' and various related terms are interwoven in the language-games and conventions appropriate to, on the one hand, the theatre, film and television drama, and on the other hand sport, are distinctly different. The result is that what constitute the appropriate occasion-sensitive understandings of the utterances in which those terms play a part within the 
relevant language-games on specific occasions differs. With those differences the logical consequences (what follows) of the use of such terms in different contexts, on specific occasions, within particular language-games are quite different. Failure to appreciate those things is partly constitutive of a failure to grasp the various language-games and the practices within which they are interwoven.

\section{A distinction to be made: differences between sport and drama}

Someone might think that all that has been done here is that a stipulative definition of 'drama' has been smuggled in the back door while all this talk of the use of the terms 'dramatic' and 'tragic' creates a diversion. The idea being that, in the end, all I am doing is insisting that one use is the 'correct' use and all the others are dismissed as 'figurative' and, in some cases, more specifically, 'metaphorical'. Best (1978: 121) anticipated an objection along those lines in relation to his distinction between sport and art, but pointed out that, while philosophers have no business policing our use of language, in the end, no matter what we call things, there will remain a distinction to be made. So even if 'art' were to be used as broadly as it is in the 'barbarously degenerate' expression 'the art of cooking', 'there would still be a distinction between those forms of activity which have, and those which do not have, intrinsic to their conventions, the possibility of comment on life issues in the way described' (Best, 1978: 121). The same point applies in relation to uses of 'dramatic' and 'tragic'. Indeed, while Best felt it sensible to preserve the term 'art' for those activities that have the possibility of comment on life issues in a particular way, most, if not all (it isn't a tragedy if someone doesn't win) uses of 'dramatic' and 'tragic' are perfectly appropriate and cause no confusion until we start trying to construct philosophical theories to show that sport, art and the aesthetic really are more closely connected than we have tended to think. That is where the trouble starts!

Whatever we want to say about the use of 'dramatic', there are differences between that which we describe in such ways in sport and those things to which we ascribe that term in the theatre, film and television (which I will call 'drama', because that is what they are called). In drama the outcome is more or less for all those watching, but in many sports half are happy and half are disappointed, so the dramatic climax is different for each group of fans. Also, the outcome in drama is the result of a creative enterprise where that outcome is pre-determined, or, in cases where improvisation is a feature, we could only be sure that there is a good chance of something with aesthetic value to the degree that the outcome is pre-determined. Equally, the things that happen in drama happen to the characters, not the actors, whereas in sport they happen to the players and athletes themselves - there's no meaningful distinction between the left-back and the person playing left-back. As a consequence, a tragic moment in the theatre is typically a success for the actor, but a failure for the character - the use of 'tragic' for a failure in sport is, therefore, figurative because there can be no failure for the character in sport as there are no characters in the relevant sense. In addition, as Best (1978: 122) pointed out 'whereas sport can be the subject of art, art could not be the subject of sport. Indeed, the very notion of a subject of sport makes no sense'. Drama has a subject 
(that subject could even be sport), but sport doesn't have a subject - an observation related to that about the lack of characters or an equivalent in sport, the lack of a creative enterprise resulting in a pre-determined outcome that is intentional (the author, director etc. chose not to change it), and to the point that the conventions of drama and the conventions of sport are very different. The rules of sport determine what actions one can attend to, as the rules make certain actions constitute sporting actions (one can't score a try in a football match, but, more importantly, one can't score a try in anything other than a rugby match). If one is to appreciate sport qua sport, then one must attend only to sporting actions, and it is there, in those actions qua sporting actions that one must find any aesthetic appreciation of sport (see McFee, 2013: 423). To cite 'dramatic' events in sport as such cases is to fail to see that to the degree that a sport is dramatic in an aesthetic sense, it ceases to be sport, for example, WWF wrestling or 'play acting' or 'feigning' a foul or injury (Mumford, 2012: 55, also see McFee, 2015: 128-9).

\section{Concluding remarks: the drama in sport}

Someone might say 'But surely sport is, or at least can be, dramatic, so it's just false to say that the drama in sport isn't proper drama'. To say that, however, is to misunderstand what the discussion here shows. It is not that there is anything wrong with describing events in sport as dramatic and talking about the drama in sport. The confusion comes from thinking that when we talk about drama in sport, we are talking about something sufficiently similar to drama in the theatre, film and television that the identification of drama in sport also constitutes the location of an aesthetic dimension to sport, and most importantly, to purposive sports. Again, it is important to be clear that purposive sports can be viewed from an aesthetic perspective, but so can more or less anything. It would, however, seem that viewing purposive sports from an aesthetic perspective is not to view them as the sport that they are, but rather as something that sometimes produces, for example, beautiful movements. That is so because the aim in trying to win in the case of purposive sports is to achieve something (such as crossing the finishing line first, scoring more goals than the opposition etc.) by any means permitted by the rules, whether those means be beautiful or ugly.

Stressing that point exposes the difficulty here for what it is; this is just a philosopher's confusion. We are perfectly capable of talking of sport as being dramatic without thinking that such properties of sport constitute an aesthetic dimension. That thought is one thought too many (Williams, 1981: 18) and a consequence of the theorising of philosophers, rather than an everyday confusion. It isn't our use of language that is in need of adjustment to fix the problem; that is in perfectly good order as it is, but rather our craving for general theories that motivates the contrivances of the philosophical problems claimed to be in need of the solutions provided by philosophical theories.

\section{Acknowledgements}


The material in this paper emerged from exploring an element of a paper read to the North American Society for Aesthetics Pacific Division meeting in Pacific Grove, California on 9th April 2015. I'm grateful to Alva Noë, David Davies, James Hamilton, Sean Kelly and Christopher Thi Nguyen for questions and comments on the paper from which this developed. I'm also very grateful to Stephen Mumford for providing me with some of his work and for the interest he has shown in the work I am doing on this and related topics. As always, I'm very grateful to Graham McFee - in this case for inviting me to that conference, and for innumerable discussions on the issues considered here, and also to my colleagues at Edge Hill, David Peimer, Victor Merriman, Goran Stanic and Mxolisi Norman for very useful discussions on some of the material here relating to drama.

\section{References}

ANJUM, R. and MUMFORD, S. 2011. 'What We Tend to Mean'. Norsk Filosofisk Tidsskrift 46 (1): 20-33.

AUSTIN, J, L. 1962. Sense and Sensibilia. Oxford: Oxford University Press.

AUSTIN, J, L. 1975. How to Do Things With Words. Second edition. Oxford: Oxford University Press.

AUSTIN, J, L. 1979. Philosophical Papers. Third edition. Oxford: Oxford University Press.

BAKER, G. P. and HACKER, P. M. S. 1980. Wittgenstein: Understanding and Meaning. Oxford: Blackwell.

BAKER, G. P. and HACKER, P. M. S. 2009a. Wittgenstein: Understanding and Meaning, Part I-Essays. 2nd ed., extensively revised by P. M. S. Hacker. Oxford: Blackwell.

BAKER, G. P. and HACKER, P. M. S. 2009b. Wittgenstein: Understanding and Meaning, Part II-Exegesis. 2nd ed., extensively revised by P. M. S. Hacker. Oxford: Blackwell.

BAZ, A. 2012. When Words Are Called For: A Defense of Ordinary Language Philosophy. Cambridge, Massachusetts: Harvard University Press.

BEST, D. 1978. Philosophy and Human Movement. London: George Allen \& Unwin.

CARROLL, N. 2008. The Philosophy of Motion Pictures. Oxford: Blackwell.

CULBERTSON, L. 2016. 'Scylla and Charybdis: The Purist's Dilemma'. Sport, Ethics and Philosophy 10 (2): 175-196. 
CULBERTSON, L. 2017. 'Purism and the category of "the aesthetic": the drama argument'. Journal of the Philosophy of Sport 44 (1): 1-14.

DUMMETT, M. 1993. The Seas of Language. Oxford: Clarendon Press.

HACKER, P. M. S. 2013. The Intellectual Powers: A Study of Human Nature. Oxford: Wiley-Blackwell.

HACKER, P. M. S. 2015. Forms of Life. Nordic Wittgenstein Review Special Issue 2015: $1-20$.

HARMAN, G., QUINE, W. V. O., KRIPKE, S., LEWIS, D., DUMMETT, M. A. E. and PARTEE, B. 1974. 'Second General Discussion Session' (Proceedings of a Conference on 'Language, Intentionality, and Translation-Theory'). Synthese, 27 (3/4): 509-521.

KRIKE, S. 1980. Naming and Necessity. Revised and enlarged edition. Oxford: Basil Blackwell.

MCFEE, G. 2004. Sport, Rules and Values: Philosophical Investigations into the Nature of Sport. London: Routledge.

MCFEE, G. 2013. 'Making Sense of the Philosophy of Sport'. Sport, Ethics and Philosophy 7 (4): 412-29.

MCFEE, G. 2015. On Sport and the Philosophy of Sport: A Wittgensteinian Approach. Abingdon: Routledge.

MUMFORD, S. 2012. Watching Sport: Aesthetics, Ethics and Emotions. Abingdon: Routledge.

TRAVIS, C. 2008. Occasion-Sensitivity: Selected Essays. Oxford: Oxford University Press.

WILLIAMS, B. 1981. Moral Luck: Philosophical Papers 1973-1980. Cambridge: Cambridge University Press.

WISDOM, J. 1965. Other Minds. 2nd ed. Oxford: Basil Blackwell.

WITTGENSTEIN, L. 1961. Tractatus Logico-Philosophicus. Translated by D. F. Pears and B. F. McGuiness. London: Routledge \& Kegan Paul. [Cited as TLP]

WITTGENSTEIN, L. 1976. Wittgenstein's Lectures on the Foundations of Mathematics, Cambridge 1939. Edited by C. Diamond. Chicago: The University of Chicago Press. [Cited as $L F M$ ]

WITTGENSTEIN, L. 2005. The Big Typescript: TS 213. Edited and translated by C. Grant Luckhardt and Maximiliam, A. E. Aue. Oxford: Blackwell. [Cited as BT] 
WITTGENSTEIN, L. 2009. Philosophical Investigations. 4th ed. Translated by G. E. M. Anscombe, P. M. S. Hacker and J. Schulte. Oxford: Wiley-Blackwell. [Cited as PI]

WITTGENSTEIN, L. 2009. Philosophy of Psychology - A Fragment, in Wittgenstein, L. 2009. Philosophical Investigations. 4th ed. Translated by G. E. M. Anscombe, P. M. S. Hacker and J. Schulte. Oxford: Wiley-Blackwell. [Cited as PPF]

Leon Culbertson, Edge Hill University, Graduate School, Ormskirk, Lancashire, UK, L39 4QP. E-mail: culbertl@edgehill.ac.uk

\footnotetext{
${ }^{1}$ The heavy reliance on direct quotations from Mumford is to try to avoid misrepresenting him.

${ }^{2}$ Both general contexts, such as sport on the one hand and the theatre, film or television on the other, and specific occasions of use.

${ }^{3}$ Like Best, Mumford rightly rejects the idea that sport could be art.

${ }^{4}$ It is important to be clear that what I offer here is an elaboration of Best's view that is derived from taking seriously the influence of Wittgenstein on his work. There is more than one way to understand Best's work, as there is Wittgenstein's. Perceptive readers who are well-versed in the work of both philosophers will notice that it is in the so-called 'radical contextualism' that my own position is most obviously one way of reading Best. This paper and related work of mine should not be understood as Best scholarship for its own sake, but as a distinct contribution to a debate in the literature that involves one way of understanding Best's work. Needless to say, it seems to me to have the most to commend it as a philosophical view of the matters under consideration.

${ }^{5}$ For two different accounts of what the exceptions might be see Baker and Hacker (1980: 250-51) and Peter Hacker's extensively revised edition - Baker and Hacker (2009a: 152-8) and (2009b: 11920).

${ }^{6}$ He also emphasises that:

'Philosophy must not interfere in any way with the actual use of language, so it can in the end only describe it.
}

For it cannot justify it either.

It leaves everything as it is' ( $P I \S 124)$

${ }^{7}$ See Hacker (2013: 454-55) for clarification of the common misunderstanding of such an approach as in some way describing supposed linguistic intuitions.

${ }^{8}$ There is no contradiction here in saying that Best is not policing language, yet there are circumstances under which drawing certain things to the attention of a competent speaker of a language should lead that person to give up some uses of language in certain circumstances - to, as it were, leave of one's own accord (cf. LFM: 103). Clearly there has to be some point at which we can distinguish sense from nonsense, but the point is that it is not at the level of the words used (a general level), such that a series of general prohibitions can be stated. Rather, whether something makes sense or not, whether someone succeeds in saying something meaningful or not, is an occasion-sensitive matter (see Travis, 2008). The appeal is not to a pre-specified set of contextless prohibitions in language use, but rather to the context-specific logic of the particular act of speech. An appeal to reason and logic is no different from what one ultimately draws attention to in the analysis of inferences, other than the important fact that the analysis of inferences is general and often founders on occasion-sensitive matters (i.e. what counts as an $F$ or as $\varphi$-ing in a given situation).

${ }^{9}$ There's nothing especially important about suspense in this context, it's just one example of a feature one might look for in drama in the theatre etc., but it certainly isn't an essential feature of such drama, nor is it the case that we don't have uses of 'suspense' outside theatre, film or television. The issues around different uses of 'dramatic' arise in a similar fashion in relation to uses of 'suspense', so we should not think the example here any better or more important than others that might be given to help someone see that in the theatre, film or television for something to be good drama requires more than, for example, a fight, even if, in a different sense, we might be correct to call a fight between two people of whom we have no knowledge 'dramatic'. Being dramatic in the sense in which a fight between two people one doesn't know is dramatic does not imply that 
something is drama in the sense in which the activities in the theatre etc. are drama and being drama in the sense of theatre etc. does not imply that something is dramatic in the sense in which a fight between two people one does not know is dramatic.

${ }^{10}$ The etymology is not important here. An indication of the context of the original use allows a contrast to be drawn between the original use and the use under consideration, which is helpful in showing something about what the use under consideration is. The original use is simply an object of comparison here to help clarify the use under consideration.

${ }^{11} \mathrm{I}$ 'm grateful to one of the anonymous reviewers for reminding me of the discussions in Kripke (1980) and Dummett (1993).

${ }^{12}$ One doesn't call the police when Gloucester's eyes are put out in King Lear. 